\title{
APPLICATION OF RISK ANALYSIS WITHIN VALUE MANAGEMENT: A CASE STUDY IN DAM ENGINEERING
}

\author{
Mohsen ROHANINEJAD ${ }^{\mathrm{a}}$, Morteza BAGHERPOUR ${ }^{\mathrm{b}}$ \\ ${ }^{a}$ Department of Civil Engineering, Iran University of Science \& Technology, Tehran, Iran \\ ${ }^{b}$ Department of Industrial Engineering, Iran University of Science \& Technology, Tehran, Iran
}

Received 4 May 2011; accepted 14 Sep. 2011

\begin{abstract}
Nowadays, considering uncertainties and complexities in dam engineering problems, implementation of risk analysis is essential more than before. On the other hand, reliability analysis is an efficient approach which can be applied in order to quantify the identified risks. By applying such analyses, a designer can therefore define and develop different scenarios in order to evaluate the effect of identified risks. The risk management process can be further implemented within a value management cycle where the potential alternatives should be evaluated and finally the best-known alternative must be selected. In order to measure the efficiency of risk analysis approach in a dam, a case study is studied and then implemented. The result of the reliability analysis for the piping phase shows a conservative approach with a low risk during the dam design process. Based on the value analysis, two different scenarios are then developed. In the first scenario, the piping phase is considered as a high risk issue; and in the second scenario, the risk is considered as its minimum acceptable threshold. Based on the obtained results, this can be summarized: utilizing risk analysis for improvement of the decision-making process can be efficiently defined and developed as a fundamental strategy in water resource projects.
\end{abstract}

Keywords: decision-making; risk analysis; reliability analysis; value management; dam engineering; Monte Carlo simulation.

Reference to this paper should be made as follows: Rohaninejad, M.; Bagherpour, M. 2013. Application of risk analysis within value management: a case study in dam engineering, Journal of Civil Engineering and Management 19(3): 364-374.

\section{Introduction}

Due to the large amount of investment spent in developing water resource projects, a special understanding is required toward dam safety issues. In general, risk is defined as a probability of occurrence for an unsatisfactory (or sometime satisfactory) operation (or an event) to be multiplied by the consequence of its failure (or enhancement). The consequences of the failure may include replacement costs, casualties, damage to the environment, and also social costs.

Risk management, on the other hand, is an important part of the project management body of knowledge with the aim of reducing the probability of unsatisfactory occurrences to be considered in different phases of a project such as design, construction, and operation. Although the goal of the risk management process is to optimize a project using analytical techniques, however, in practice, it is extensively used in order to increase the degree of safety and reliability
(Thompson 2004). The risk management process should also consider the dam as a dynamical system (Bowles et al. 1997). It is also pointed out that the risk analysis is frequently applied in other types of construction projects. Kim (2010) developed a risk performance measurement model which basically incorporated the earned value project management system. By applying this approach, he put schedule/ cost and risk performance indexes together. Zavadskas et al. (2010) applied a multi-attribute decision-making model, namely, TOPSIS to assess the risks of a mega construction project. They could consider different factors affecting construction risk management. Manik et al. (2008) applied a neural network-based model for analyzing the effect of payment risk in pavement construction projects. They showed that the error of the neural network adaption is logical and that the model can be applied for further analysis.

Generating an approximate balance between safety and its relevant cost in dam construction is

Corresponding author. Mohsen Rohaninejad

E-mail: mrohaninejad@gmail.com 
one of the strong motivations for going through extensive researches in this field (Stewart 2000). Within this framework, utilizing the value engineering approach may likely increase the efficiency of a design; however, by comparing the value engineering and risk management processes, it can be stated that the integration of these procedures has some difficulties, but however, has many advantages as well as other hybrid approaches and well-tuned integrated systems.

Since the first step of implementing a risk management process is to focus on potential risk, therefore, the following observations for the risk identification stage are taken into further considerations.

Based on the existing evidences of a dam, located in Iran, the piping section is expected to be the most serious failure mode in this dam due to some issues such as corrosion, pitting, etc. The length of the dam is about $15 \mathrm{~km}$. Seepage from the foundation of the dam is important because of the large thickness of the alluvial layer. Considering length of the dam, a high variation of permeability coefficients, existence of sand lens in the foundation, and the absence of a cut-off wall in some regions can be seen. Therefore, the piping phase and intensive seepage in some zones of the dam foundation are likely expected to occur. In this dam, the seepage controlling element includes vertical and horizontal drains, upstream blanket, and relief wells. Downstream berm and a clayey cut-off wall were also constructed only in some specific sections. In order to utilize the concept of risk and value management in this dam, risk analysis is implemented through the piping phase.

\section{Risk analysis concepts in dam design}

As the second stage in the risk management process, after risk identification, risk analysis and risk assessment should be carried out. Akintoye and Maleod (1997) discussed how to implement risk management in construction projects. However, by going through existing researches in the literature, the applications of risk management in dam construction is not documented as a standard practice yet. It is still a novel and an open topic for research and development since many research gaps have been found there. In the late 1980s, some attempts have been made toward the risk assessments in different dams, e.g. Tongue River dam risk assessment (PRC Engineering 1987) and design of a dam on karst in Florida (Vick, Bromwell 1989). As previously mentioned, by some other researchers (Salmon, Hartford 1995; Hartford, Baecher 2005), disadvantages of such procedures may come from the fact that estimation of the probability of occurrence is performed based on expert judgments which may be associated with many errors and bias.

Figure 1 explains the process of risk analysis for a typical dam. The actions are known with the definite

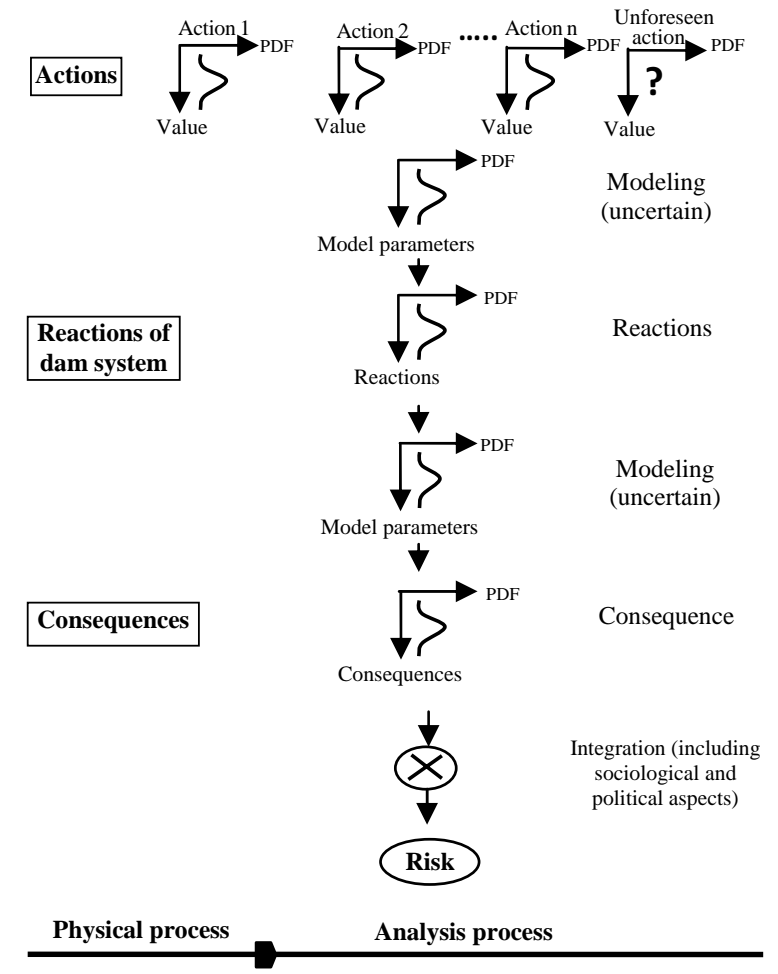

Fig. 1. Risk analysis processes for a typical dam

probability of occurrence (inflow of water, water level in reservoir, earthquake, etc.) They are used as inputs to be further applied through uncertain models, leading to the probability distribution of response values (deformation, stresses, and other parameters). These consequences expressed as the uncertain functions of the probability of occurrence are known as the risk components (Darbre 2000).

It is also pointed out that there are several forms of risk analysis including the risk indexing techniques, portfolio risk analysis, qualitative analysis, semiquantitative, and precise quantitative risk analysis (QRA), which is sometimes called probabilistic risk analysis (PRA) (Fell et al. 2000, 2001). Because each dam characteristic and its behavior is uniquely known, qualitative approaches for assessing dam safety still remains a challenging issue. Therefore, some procedures addressed the probability of failure of dams to be further applied through a quantitative risk assessment for all failure modes (Donnely 2006). Some failure modes of embankment dams like overtopping and liquefaction also are well developed. However, some others like piping and internal erosion are less understood (Fell et al. 2000) which is focused in this paper.

\section{Quantification of piping risk for an embankment dam}

A new aspect of geotechnical analysis in embankment dams based on risk assessment has been widely considered in the existing works and researches carried out in this area. The reason for such concerns 
comes from uncertainties associated with the selected geotechnical parameters. These uncertainties arise from physical uncertainties, human errors, and also uncertainty in the modeling procedure. However, the combination of these unknown parameters may lead a designer to generate an unreliable design. It is also pointed out that most of the engineering analyses in the conventional approaches are incomplete because the designing process is not fully implemented using an appropriate holistic approach. Thus, any analytical approach determining the failure probability is required to compute the entire relevant mechanisms and their effectiveness (Stewart 2000). As mentioned earlier, this paper focuses on quantifying the piping risk of a dam. Reliability analysis is one of the methods which can be efficiently used in this respect.

In a probabilistic modeling procedure, variables are divided into two main categories; namely, load variables. Due to this categorization, a simple form of a limited state function can be defined according to Eqn (1) in which there is an implicit or explicit relationship between variables and the degree of safety of a model. Accordingly, a Limit State Equation (LSE) can be defined where $Z=0$ :

$$
\begin{aligned}
& z=Z(r, s) ; \\
& \text { LSE }: z-1=0 .
\end{aligned}
$$

Therefore, the LSE clarifies two different regions: one happens where LSE $\geq 0$ and the other happens otherwise. In this case, $r$ is a vector of resistance variables and $s$ indicates a vector of load variables. However, in complex problems, such as the case presented in this research, there is an implicit LSE in which the relation between stress and resistance is not explicitly known.

Also as it is previously pointed out, there is no specific procedure to determine the failure probability of internal erosion and piping, which are the most important issues of most embankment dams. Foster et al. (2000) presented an approach for the evaluation of failure probability due to piping phenomena. The probability of failure is estimated by adjusting the historical frequency of piping failure. This procedure can be performed according to weight factors which are taken into account: the dam zoning, filters, age of the dam, core soil types, relative density, foundation geology, dam performance, and monitoring. Lacasse et al. (2004) evaluated the risk of piping based on engineering judgments. In an attempt to investigate the piping risk, Badv and Sargordi (2001) utilized LSE incorporation in the experimental relation of Sellmeijer and Koenders (1991) that seemed quite unreliable.

The finite element analysis is the only method to evaluate LSE without the loss of accuracy: an explicit term for the limit state equation. In addition to utilizing the finite element analysis, there is a need to use probabilistic techniques in engineering problems as they provide an understanding of failure mechanisms in depth. Hence, to accomplish these advantages, a well-defined model of the structure embedded with a reliability technique is required (Rajabalinejad 2009). On the other hand, The Monte Carlo simulation is extensively considered as the most efficient and commonly applicable procedure for probabilistic modeling. Therefore, the combination of numerical models together with the Monte Carlo simulation is an appropriate approach for going through the reliability analysis. The reliability-based approach relies on selecting effective design parameters that satisfy a desired degree of reliability or a certain probability of failure. The reliability index can be obtained as follows:

$$
\beta=\frac{m_{\mathrm{FS}}-L}{\sigma_{\mathrm{FS}}},
$$

where $m_{\mathrm{FS}}$ is the mean factor of safety, $L$ is a limit state value usually equal to 1 , and $\sigma_{\mathrm{FS}}$ is the standard deviation of the factor of safety (Elkateb et al. 2003). As shown in Figure 2, with the determination of $\beta$, the reliability of a dam can almost be predicted according to considering the failure mode (Phoon 2004).

Since the Monte Carlo simulation analysis is a random and stochastic-based approach, to summarize the framework of the random-based variable system, the following stages can be elaborated:

(1) Identifying all parameters which may control the risk and reliability analysis (risk identification step).

(2) Defining the parameters as random variables in the failure modes and then fitting appropriate statistical distribution (input analysis).

(3) Constructing a suitable reliability model in accordance with statistical models and ran-

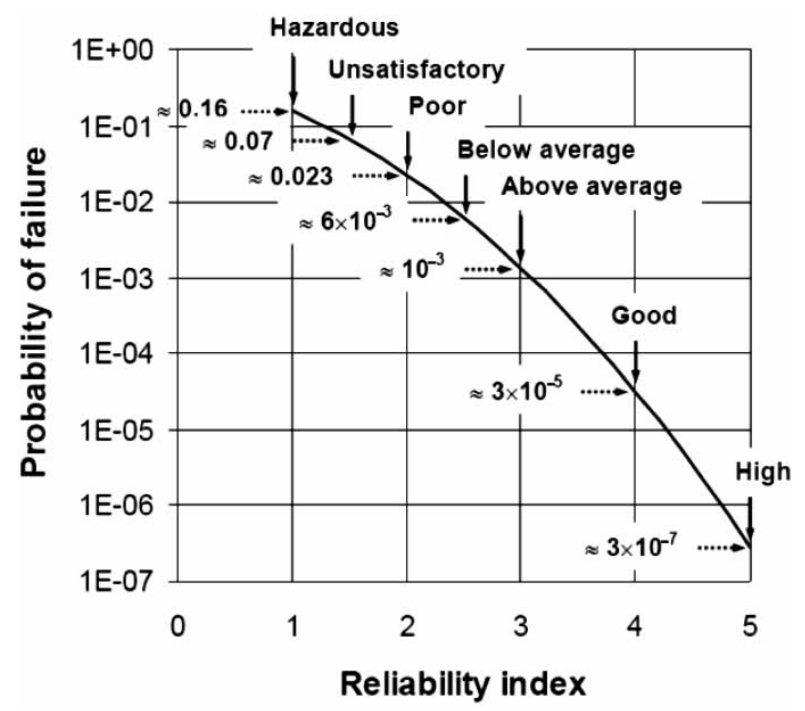

Fig. 2. Assessment of dam safety levels with the reliability index 
dom controlling variables (modeling procedure).

(4) Clarifying indefinite limits and probability distribution generation to determine the probability of failure modes (output analysis).

To run a probabilistic analysis, a new code is developed using FLAC $^{\mathrm{TM}}$. FLAC is a two-dimensional software for modeling the behavior of the soil, rock, and other structures and their interaction with water, and it can be further used in the batch mode. The equations of FLAC are as follows. The fluid transport is represented by Darcy's law:

$$
q_{i}=m_{i j} k(s) \frac{\partial}{\partial x_{i}}\left(P-\rho_{w} g x\right),
$$

where $q_{i}$ is the specific discharge vector, $m_{i j}$ is the mobility coefficient, $k(s)$ is the relative permeability as a function of the saturation $s, P$ is the fluid pressure, $\rho_{w}$ is the density of fluid, and $g$ is the gravity value. The fluid mass balance equation is:

$$
\frac{\partial \lambda}{\partial t}=-\frac{\partial_{q i}}{\partial_{x i}}+q_{v}
$$

where $\lambda$ is the variation of fluid content in time $t$ and $q_{v}$ is the volumetric fluid source intensity. The balance of momentum can be obtained as follows:

$$
\frac{\partial \sigma_{i j}}{\partial x_{j}}+\rho g=\rho \frac{d u_{i}}{d t},
$$

where $\rho=(1 n) \rho s+n \rho w$ is the solid bulk density, $\rho_{s}$ and $\rho_{w}$ are the densities of the solid and fluid phase, respectively, and $n$ is porosity.

The solution procedure in this study provides the FLAC software with desired PDFs of the input variables, enables the software to calculate the different adapted phases, and finally generates the desired outputs. In fact, along with each variation in soil parameters, a new problem is modeled and then solved. According to the simulation process, the variation of the input parameters provides a wide range of possible combinations of the different variables under the assumed PDF.

\section{Value management and risk analysis for a dam: a hybrid approach}

Value management has been individually applied through many construction projects. Chen et al. (2010) discussed how to measure the overall performance of the value engineering workshop for projects. Lee et al. (2010) applied a performance measurement model based on value management principles to a highway construction project. They show that this model can generate a significant money saving. Similarly, Kwok et al. (2010) applied a cost-driven value management model in railway projects which were located in Hong Kong and they also show a significant saving in costs. Although a lot of value engineering and risk management models are individually found, no research was carried out in the area of hybrid value management - risk analysis within dam engineering problems.

During implementation of the value management cycle, normally in brainstorming phase, some novel and potential alternatives are suggested by incorporating expert judgments. These alternatives, however, associated with some risks should be further managed. Hereby, in the traditional value management approaches, some common techniques such as standard decision-making models are typically applied in order to analyze the efficiency of the proposed alternatives. However, here, a risk-based analysis through the value management cycle is absent in order to enable a designer to know about the risks associated with the generated alternatives. It is therefore a novel approach to apply risk analysis and the reliability-based model through value management system in the alternative selection process.

The academic committee of management and value analysis in Oxford University in 1997 made an attempt to integrate these two techniques together (value and risk management) (Thompson 2004). Green (2001) believed that the first step toward the integrated approach is to dispose the language of value and risk to the benefit of the language of uncertainty. He argued that value management seeks to solve uncertainty along with the goals of a project. Therefore, when risk analysis and value management are expressed in terms of uncertainty, their inner- dependencies become more obvious. Kirk (1995) recommended a generalized approach for the value management cycle, so that in the conventional plan of value management, risk management process was included together with the qualitative, quantitative, and the implementation of risk-decreasing strategies. Leung et al. (2002) used qualitative and quantitative studies to identify conflicts among the project participants. They believes to yield an optimum level of satisfaction, a value manager should stimulate conflicts at the early stage of the value management workshop.

In the common approaches of the value engineering cycle, the risks analysis is not normally considered. Therefore, developing a modern value management model is needed to utilize risk analysis in order to reduce proposal's risk effects on the project goals. By comparing the models of value engineering and risk analysis, it is revealed that value engineering is attempted to increase the value of a project by using novel ideas; whereas, risk analysis is pursued to increase the safety of a project. Therefore, defining the safety concept, as an element of rising value, can be joined with the commonly developed value engineering model. The value management cycle should be incorporated 
with the risk management process to recognize and analysis the potential risks of affected project goals.

In the proposed model, risk analysis as a reversible cycle is incorporated to a value management cycle to evaluate the innovating ideas by quantifying their impacts on project goals and then generating suitable strategies as a response to the high-priority identified risks. Through this framework, in order to analyze the risk degree, the project faces the execution of the scenario; the risk of any scenario should be included in the evaluative stage of the value cycle. Therefore, the cost of risks in developing value engineering is a criterion of ranking and developing ideas generated in the value management cycle. In Figure 3, an example of this type of model is presented.

Risk and value management have complementary relations with each other. With risk analysis, a high potential output can be achieved and performing value management approach focus on earning more value by preventing the unnecessary processes. The main objective of using risk analysis is to quantify the needs of beneficiaries, which is required in the value management processes. Therefore, performing the mentioned procedures, cost-benefit analysis of each scenario which are proposed in the processes of value engineering, can be easily assessed. In this study, by introducing new scenarios and using risk analysis, a novel procedure is proposed. In Figure 4, a systematic procedure of the proposed methodology is presented.

\section{A case study: a dam}

In order to show the applicability of the solution procedure applied in this paper, a case study has been considered. A summary of the dam characteristics is given in Table 1. The whole data has been observed through a site visit or derived from the other historical information available in previous reports. Input data are given in Tables 1 and 2 and Figure 4. These inputs may affect cost savings and safety risks which are considered as output. The importance of the selected inputs and outputs can be initially found according

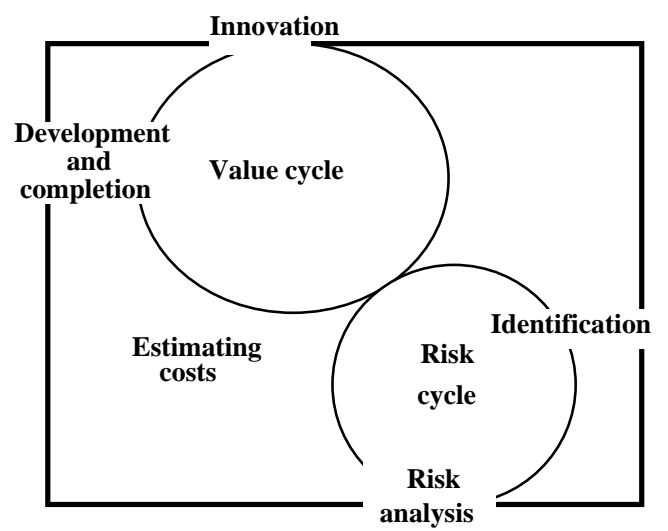

Fig. 3. Risk analysis within the value cycle the logical relationships among inputs and outputs while further detail analysis can be applied by using the simulation study.

\section{Value analysis in the case study}

As pointed out earlier, regarding the initial analyses, the piping section is expected to be the major risk for this dam. To perform the value cycle, functions related to various elements to reduce the risk are being evaluated. This evaluation process is presented in Table 3. In addition, to clarify the relation of these elements a Functional Analysis and System Technique (FAST) diagram is illustrated in Figure 5.

According to the FAST diagram used to reduce the piping risk, six elements should be included for further analysis. Regarding to the length of the dam $(15 \mathrm{~km})$, constructing the cut-off wall and injection options cannot be a logical selection. To evaluate the efficiency of remained elements, the dam with blanket, relief wells, drainage, and downstream berm is analyzed to compute the risk of the main model. Then, in the first scenario, only drain characterization is considered and the other elements are not taken into account. In the second scenario, drain, relief wells, and downstream berm are being involved in the simulation analysis whereas the remaining elements are neglected.

\section{Preliminary findings and research investigations}

To implement the reliability analysis of piping, after identifying the effective variables and defining the probabilistic distribution function, by using the finite difference software (FLAC), Monte Carlo simulation process was implemented. To run the probabilistic analysis, a computer program was developed interactively with FLAC. This code feeds the FLAC with the desired probability density function for the input variables, invokes the software to calculate the different adapted phases, and finally gathers the required outputs. In fact, along each variation in the soil parameters, a new problem is defined and then solved. According to the simulation process, the variations of the input parameters provide a wide range of possible combinations of different variables, under the assumed probability distribution function (PDF). Results of the stochastic numerical analysis include total discharge, exit gradients in significant parts of the dam, and the safety factor against the piping in the horizontal drain and downstream. Then, the results were saved in a Notepad file, which were submitted to MATLAB ${ }^{\circledR}$ in order to summarize the data. By evaluating the results, the probability of failure due to piping phenomena can be estimated.

Considering the results of probability failure and reliability index, if the reliability study yields un-satisfactory results, several scenarios can be further adapted in order to increase the safety of the dam 


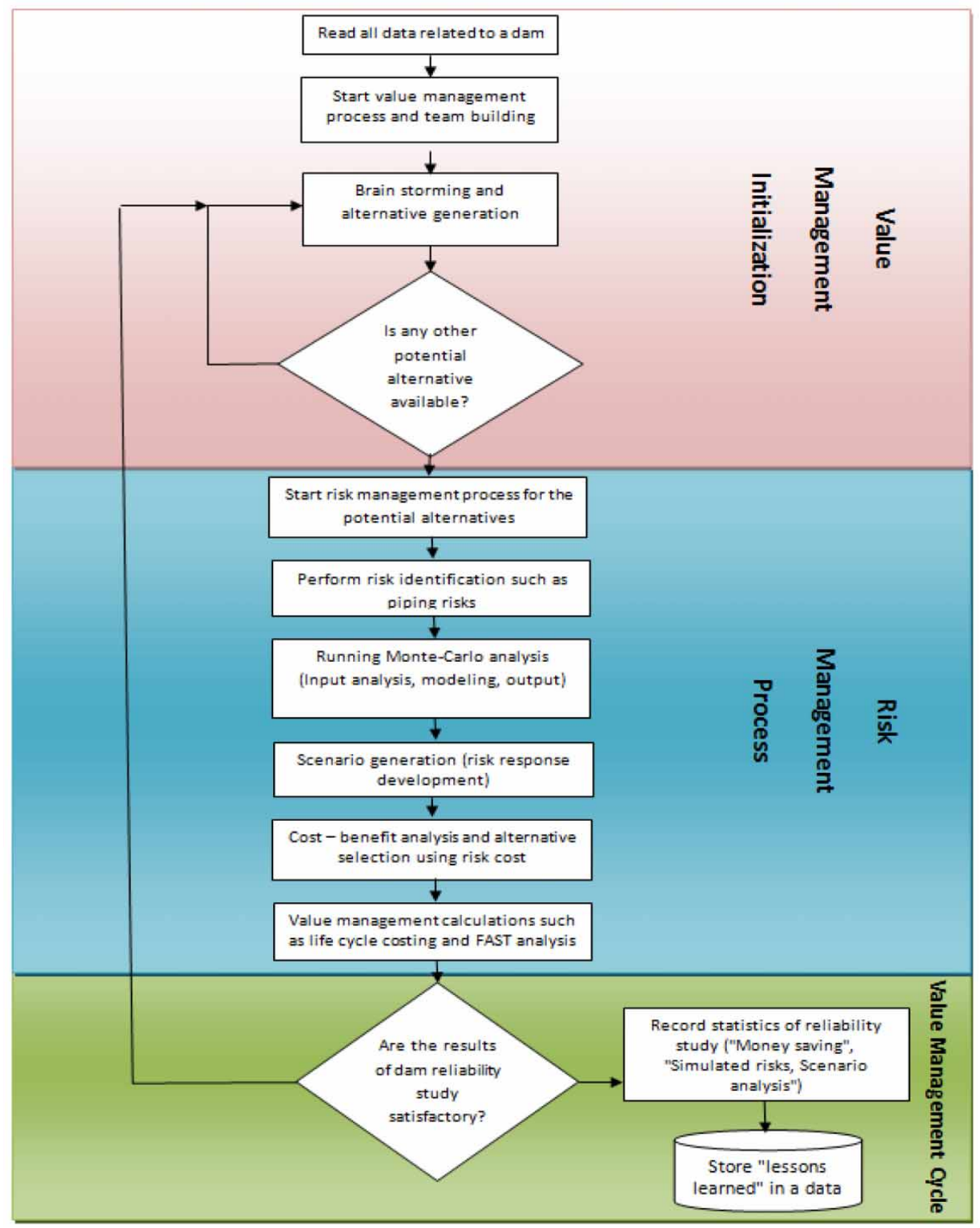

Fig. 4. Systematic framework of the proposed approach

using parameter tuning and controlling elements like upstream Blanket, relief well, downstream berm, and cut-off wall. Alternatively, if the obtained index is high, by eliminating these elements, the optimum design of the dam can be achieved. By studying the results of these analyses, we can find the efficacy of the controlling element on dam safety. One of the controlling elements of seepage is the vertical drain in the body of the dam. With respect to the low height of the dam $(15.5 \mathrm{~m})$ and due to prediction of four meters of freeboard, our analyses show that the whole length of the vertical drain has not been in direct contact with the water flow in the dam's body. Proving the fact that using Monte Carlo simulation and probabilistic finite difference analyses, an appropriate design can be carried out; the two followings steps are taken into considerations. At the first, the perme-

Table 1. Dam specifications

$$
\text { No. } 4 \text { Chahnimeh dam }
$$

Dam type: homogeneous Crest length: 15250 meter embankment

Crest width: 8 meter

Height from foundation:

15.5 meter

Upstream inclination: 1 to $3.5(\mathrm{~V} / \mathrm{H})$
Foundation width: 105.5 meter Reservoir volume: $820 \mathrm{MCM}$ at normal level

Downstream inclination: 1 to $3(\mathrm{~V} / \mathrm{H})$ 
Table 2. Summary of field results

\begin{tabular}{|c|c|c|c|c|c|c|}
\hline Specifications & & Maximum & Minimum & Average & $\begin{array}{l}\text { Standard } \\
\text { deviation }\end{array}$ & $\begin{array}{l}\text { Coefficient of } \\
\text { variation }\end{array}$ \\
\hline \multirow{4}{*}{$\begin{array}{l}\text { Coefficient of } \\
\text { permeability }(\mathrm{cm} / \mathrm{s})\end{array}$} & First layer & 0.0075 & $1.40 \times 10^{-6}$ & $6.12 \times 10^{-4}$ & $13.60 \times 10^{-4}$ & 220 \\
\hline & Second layer & 0.0032 & $1.40 \times 10^{-6}$ & $3.95 \times 10^{-4}$ & $7.22 \times 10^{-4}$ & 183 \\
\hline & Third layer & 0.0033 & $1.60 \times 10^{-6}$ & $4.87 \times 10^{-4}$ & $7.50 \times 10^{-4}$ & 154 \\
\hline & $\begin{array}{l}\text { Saturated density } \\
\left(\mathrm{kN} / \mathrm{m}^{3}\right)\end{array}$ & 18.40 & 14.00 & 15.38 & 0.77 & 5 \\
\hline
\end{tabular}

ability of the upstream body is considered as a stochastic parameter, then, by estimating the amount of pore pressure in the horizontal drain level, an effective length of the vertical drain, which in different cases of simulation cuts the zero pressure line, will be determined. With this practice, the efficiency of the drain can be evaluated. Considering the fact that we do not have access to sufficient data in order to gain real coefficient variation of upstream body soil, the suggestion of Harr is employed and the coefficient is considered equal to $240 \%$ (Harr 1987).

In addition, to evaluate other controlling elements of seepage, two scenarios are generated. In the first scenario, blanket, relief well, and downstream berm are eliminated; and in the second scenario, with respect to the results of the first scenario, only Blanket is removed. After these eliminations, the numerical model is developed and reliability analysis is then successfully implemented.

\section{The results and discussions}

After obtaining the results of Monte Carlo simulation and determining the failure probability and reliability indexes, new features can be achieved toward the dam's stability against piping phenomena. A summary of the simulation results is presented in Table 4. By substituting the average and standard deviation of the safety factors given in Eqn (2), the reliability index in the horizontal drain and downstream of the dam were obtained and was equal to 5.48 and 4.94, respectively. These facts and figures, according to Figure 2, show that the safety level of the dam can be considered as a high-level safety. On the other hand, as previously shown, the safety factor for different situations are greater than 1, it can be noted that the probability of failure will be less than $10^{-4}$. Considering Figure 2 and the amount of $\beta$, the failure probability can be predicted at about $3 \times 10^{-7}$, which is an acceptable level for water resource constructions.

As mentioned earlier, one important objective of implementing the reliability and risk analysis is the logical and appropriate design of a structure. Based on the results of this investigation, it seems that due to some important existing elements such as blanket and relief well, achieving a sufficient level of performance confidence can be accessible and even designing of the dam can be considered somewhat conservative. However, constructing downstream berm and clayey cutoff wall do not seem necessary for further analysis. As a result, using reliability-based design techniques can be helpful for this purpose.

Table 3. The functions of elements, advantages, and disadvantages

\begin{tabular}{|c|c|c|c|c|c|}
\hline Elements & Body of dam & Blanket & Relief wells & Downstream berm & Drainages \\
\hline Advantages & $\begin{array}{l}\text { - Make blockage } \\
\text { against water } \\
\text { - To create water } \\
\text { resource }\end{array}$ & $\begin{array}{l}\text { To increase } \\
\text { seepage length } \\
\text { - To decrease } \\
\text { exit gradients }\end{array}$ & $\begin{array}{l}\text { - To release pore } \\
\text { pressure in } \\
\text { downstream } \\
\text { - To stop } \\
\text { formation } \\
\text { of piping }\end{array}$ & $\begin{array}{l}\text { - Being stable in } \\
\text { downstream } \\
\text { zone } \\
\text { To stop } \\
\text { formation } \\
\text { of piping }\end{array}$ & $\begin{array}{l}\text { - To convey } \\
\text { seepage water } \\
\text { in safe way }\end{array}$ \\
\hline Disadvantages & - & $\begin{array}{l}\text { - To increase } \\
\text { costs } \\
\text { - Difficulty in } \\
\text { construction } \\
\text { - To increase } \\
\text { maintenances } \\
\text { cost }\end{array}$ & $\begin{array}{l}\text { - To increase costs } \\
\text { - Difficulty in } \\
\text { construction } \\
\text { - To increase } \\
\text { maintenances } \\
\text { cost }\end{array}$ & - & $\begin{array}{l}\text { - To increase } \\
\text { maintenances } \\
\text { costs } \\
\text { To decrease } \\
\text { dam stability }\end{array}$ \\
\hline Cost (M\$) & 36.341 & 24.723 & 1.07 & 6.711 & 13.556 \\
\hline
\end{tabular}




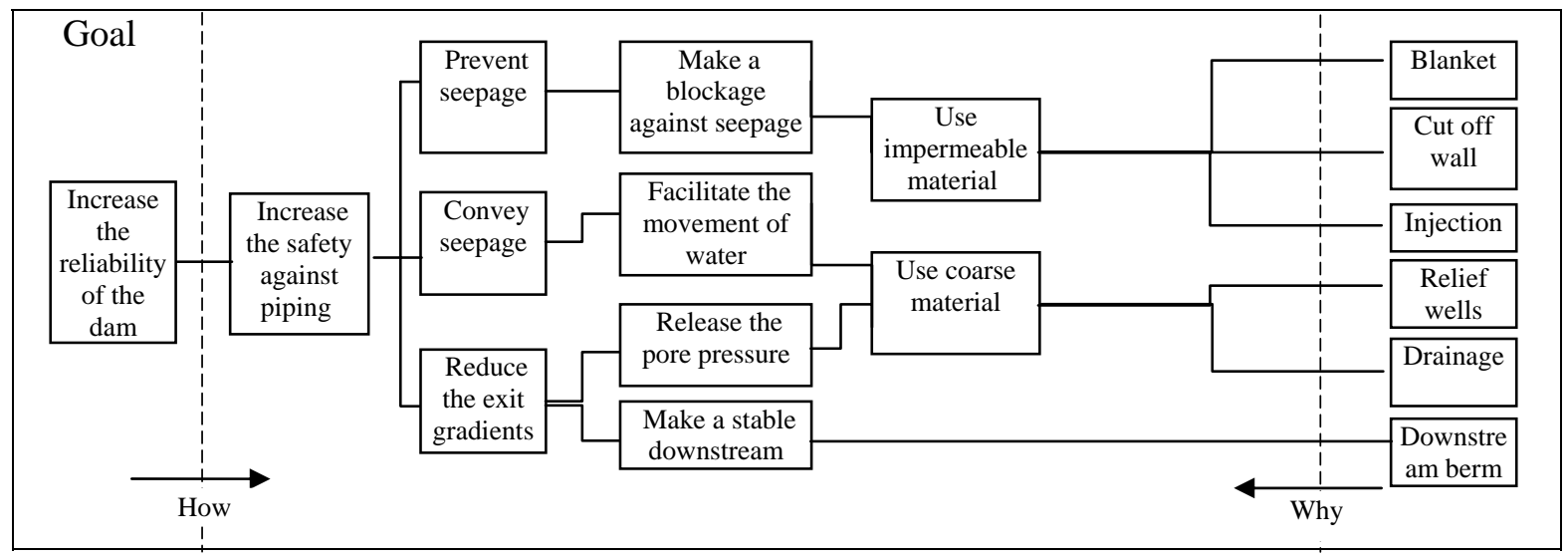

Fig. 5. FAST diagram for the dam

\subsection{Study on the vertical drain in body of the dam}

In this section, by utilizing the probabilistic finite difference analysis, efficiency of the vertical drain is evaluated. Figure 5 presents a histogram and cumulative density function of water pressure in the horizontal drain level. As seen earlier, in this figure, the average water pressure recorded at this point is about 35kilo Pascal, which seems only about $3.5 \mathrm{~m}$ of the height of the vertical drain that has been used and the rest is unnecessarily included. Of course, the great variations in Figure 6 are generated due to considering the variation coefficient equal to $240 \%$ for the permeability of the dam body soil. With respect to the fact that filter and drain materials are expensive ones to be further applied in the dams' construction, optimum designing of this element can be efficient from both economical and time-consuming point of view in such projects. Based on this analysis, it can approximately decreased $16 \%$ the volume of construction of filter and drainage and this decrease has a result in money saving approximately $\$ 2.2$ million in construction cost. In this respect, many scenarios were initially proposed in the brainstorming phase, however, considering practical limitations, safety issues, and other affecting constraints, only possible scenarios can be further studied. Anyway, generally, it is a need to organize a brainstorming by incorporating relevant technical and financial experts to evaluate the effect of each scenario from both technical and financial aspects. The selected scenarios will then be passed for further value engineering-based analysis, i.e. simulation study. In this paper, only two scenarios were appropriately selected.

In the above figure, left chart, the vertical axis indicates the frequency of observations resulting from Monte Carlo simulation study. The P7 stands for indicating the behavior of a point in a mesh analysis using simulation replications in several iterations.

\subsection{Results of the first scenario}

In the first scenario, based on expert judgments, blanket, relief well, and downstream berm were eliminated. With eliminating these elements $\$ 32.5$ million can be saved in the construction costs, that is $40 \%$ of the direct total cost. A summary of the results of this scenario is presented in Table 5. The coefficient of variation of $25 \%$ in safety factor output shows high dispersal of the available data. The average of the quantities of exit gradients is very high and the safety factor is very low. The reliability index determined in the dam is 2.2 and in downstream it is equal to 1.4. During the simulation running of this scenario, 12 safety factor cases inside the dam and 150 cases in downstream was less than one, which has resulted in predicting failure probabilities equal to $0.48 \%$ and $6 \%$, respectively. Based on the evaluation of the results and with respect to Figure 2 as selection criterion, designing by considerations of this scenario does not provide adequate resistance confidence against piping risks.

Table 4. The results of Monte Carlo finite element simulation

\begin{tabular}{lcccc}
\hline Simulation outputs & Maximum & Minimum & Average & Coefficient of variation \\
\hline Vertical gradients from foundation to horizontal drain & 0.58 & 0.026 & 0.133 & 66.79 \\
Vertical gradients in downstream & 0.47 & 0.060 & 0.144 & 45.06 \\
Safety factor against piping inside of dam & 2.57 & 1.30 & 2.01 & 8.59 \\
Safety factor against piping in downstream of dam & 2.20 & 1.12 & 1.83 & 9.15 \\
Safety margin against piping inside of dam (kPa) & 13.18 & 6.77 & 9.24 & 9.48 \\
Safety margin against piping in downstream of dam (kPa) & 11.77 & 1.84 & 7.80 & 17.56 \\
\hline
\end{tabular}



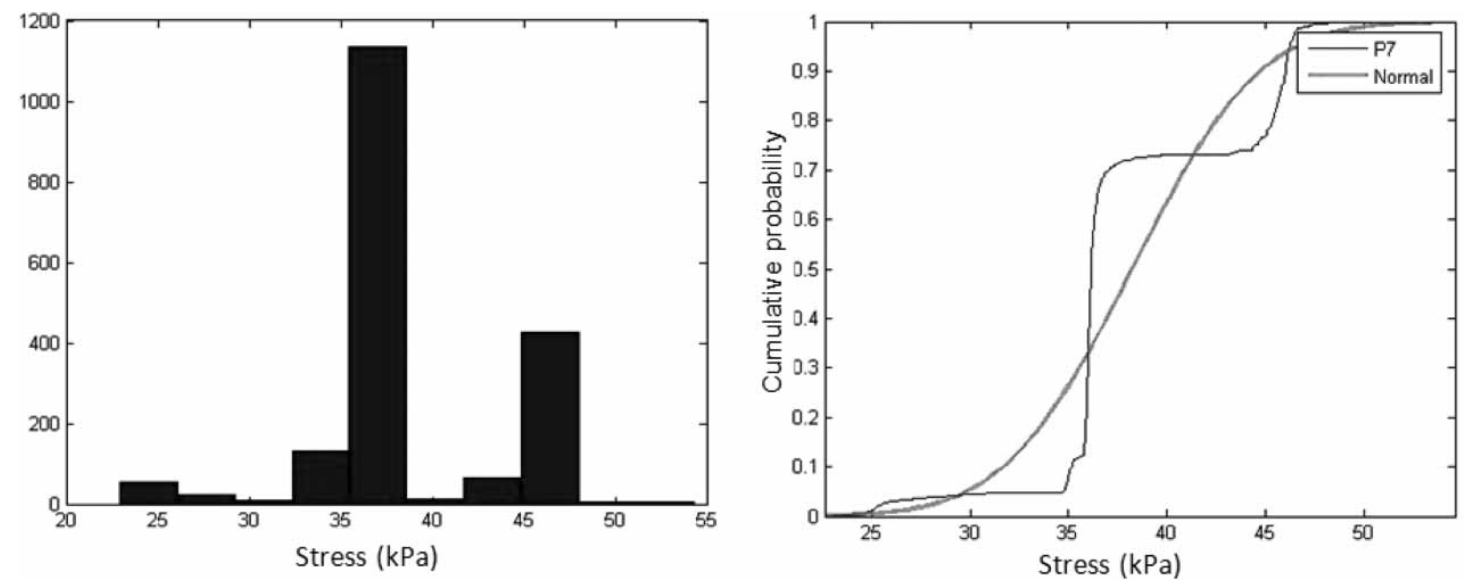

Fig. 6. Histogram and CDF of pore pressure in horizontal drain level

\subsection{The results of the second scenario}

In the second scenario, only blanket was eliminated. By eliminating this element, $\$ 24.7$ million can be saved in the construction costs, which is $30 \%$ of the total direct cost. A summary of the results of this scenario is presented in Table 6 . The average quantities of exit gradients and safety factor are evaluated as balanced amounts. The reliability index for inside the dam is determined to be 8.92 , for upstream of well 7.83 , and for downstream well 3.22. During the execution of simulation, only 20 safety factor cases in downstream well were less than one, which resulted in predicting failure probabilities equal to $0.8 \%$ for this scenario. According to Figure 2, reliability against piping risks for this scenario in the dam and upstream well is predicted to be very high and for downstream well to be above average. The decrease of the index in downstream well can be attributed to the lack of berm in these regions. Consequently, based on these outcomes, it seems that designing with this scenario, despite a certain level of risk, is suitable and efficient from an economic point of view. Cost analysis shows that relief wells and downstream berm are more efficient than blanket. Constructing blanket is more time-consuming than other elements and it needs special site consideration to construct properly. In addition, it can be predicated remedial actions concurrent with the continuous monitoring of the problematic regions.

Other scenarios can also be generated in order to design the dam effectively. For example, relief well and downstream berm can be eliminated, and only blanket or cut-off wall would remain. By defining various scenarios, beneficial information can be obtained. These information can be helpful in the project construction management, for instance, with proper information about the uncertainties, the stages of implementation of some of the elements can be moved back or forth. It is obvious such time-saving and refusal to construct unnecessary structures can be considered the advantages of reliability and risk analyses throughout the dam.

\section{Conclusion remarks and further recommendations}

In this study, using both finite difference model and Monte Carlo simulation, the risk analysis of piping phenomenon for a dam within a value-based model has been studied. The results indicate that the dam demonstrates high reliability in terms of piping phenomenon and seems to be safe during construction. In order to reach the optimum design, with incorporating value analysis, a novel hybrid methodology, in this paper, is utilized. Outputs show new perspectives in the developed model of value management for design and construction projects. According to two different scenarios made in this study, $30 \%$ and $40 \%$ of the total direct construction costs can be saved, respectively. Although it is an appropriate finding, however, not only cost savings but also safety risks should be taken into account during selection procedure. By the implementation of such procedure, the effectiveness of dam designing can be increased and

Table 5. Monte Carlo finite difference simulation for the first scenario

\begin{tabular}{lcccc}
\hline Simulation outputs & Maximum & Minimum & Average & Coefficient of variation \\
\hline Vertical gradients from foundation to horizontal drain & 1.76 & 0.068 & 0.648 & 53.76 \\
Vertical gradients in downstream & 1.80 & 0.180 & 0.666 & 50.87 \\
Safety factor against piping inside of dam & 2.43 & 0.68 & 1.67 & 17.92 \\
Safety factor against piping in downstream of dam & 2.02 & 0.52 & 1.38 & 20.06 \\
\hline
\end{tabular}


Table 6. Monte Carlo finite difference simulation for the second scenario

\begin{tabular}{lcccc}
\hline Simulation outputs & Maximum & Minimum & Average & Coefficient of variation \\
\hline Vertical gradients from foundation to horizontal drain & 1.07 & 0.129 & 0.444 & 35.97 \\
Vertical gradients in downstream & 0.83 & 0.048 & 0.277 & 50.49 \\
Safety factor against piping inside of dam & 2.55 & 1.93 & 2.13 & 5.95 \\
Safety factor against piping in upstream of relief well & 3.29 & 2.01 & 2.74 & 8.12 \\
Safety factor against piping in downstream of relief well & 1.97 & 0.50 & 1.49 & 10.18 \\
\hline
\end{tabular}

appropriate decisions can be further made regarding dam reliability. Therefore, the potential scenarios have been taken into the Monte Carlo simulation and finite element method and the best-known alternative has been selected throughout a cost-benefit analysis. Further researches can be focused on considering fuzzy logic/stochastic modeling through risk assessment of a dam.

\section{Acknowledgments}

The authors appreciate the Water Resources Management Company for financial support of this research under the grant No. Dam 1-88013. The authors also thank the Tehran Sahab Company for providing information regarding the case study. This paper also received useful comments from Prof. Noorzad, Prof. Afshar, Dr Zarghaami, and $\mathrm{Mr}$. Brojerdi. The authors also acknowledge the referees for their constructive comments which considerably improved the quality of this research over its earlier version.

\section{References}

Akintoye, A. S.; MacLeod, M. J. 1997. Risk analysis and management in construction, International Journal of Project Management 15(1): 31-38. http://dx.doi.org/10.1016/S0263-7863(96)00035-X

Baker, S.; Ponniah, D.; Smith, S. 1999. Risk response techniques employed currently for major projects, Construction Management and Economics 17(2): 205-213. http://dx.doi.org/10.1080/014461999371709

Badv, K.; Sargordi, F. 2001. An investigation into the risk of piping at dams in the Urmia region, Iran, Iranian Journal of Science \& Technology 25(B4): 625-634.

Bowles, D.; Anderson, L.; Glover, T. 1997. A role for risk assessment in dam safety management, in Proc. of the 3rd International Conference Hydropower'97, Trondheim, Norway, 1997, 111-121.

Chen, W. T.; Chang, P.-Y.; Huang, Y.-H. 2010. Assessing the overall performance of value engineering workshops for construction projects, International Journal of Project Management 28(5): 514-527. http://dx.doi.org/10.1016/j.ijproman.2009.08.005

Darbre, R. G. 2000. Probabilistic safety assessment of dams, in Proc. of the 20th Congress on Large Dams, International Commission on Large Dams (ICOLD), Beijing, China, 2000, 185-194.

Donnelly, C. R. 2006. Safe and secure - risk based techniques for dam safety. International Water Power and Dam Construction, Wilmington Media Ltd. 7 p.

Elkateb, T.; Chalaturnyk, R.; Robertson, P. K. 2003. An overview of soil heterogeneity: quantification and implications on geotechnical field problems, Canadian
Geotechnical Journal 40(1): 1-15.

http://dx.doi.org/10.1139/t02-090

Fell, R.; Bowles, D.; Anderson, L.; Bell, G. 2000. The status of methods for estimation of the probability of failure of dams for use in quantitative risk assessment, in Proc. of the 20th Congress on Large Dams, International Commission on Large Dams (ICOLD), Beijing, China, 2000, 76-96.

Fell, R.; Wan, F. C.; Cyganiewicz, J.; Foster, M. 2001. The time for development and detectability of internal erosion and piping in embankment dams and their foundation. UNICIV Report No. R-376, School of Civil and Environmental Engineering, the University of New South Wales, Sydney, Australia. 38 p.

Foster, M. A.; Fell, R.; Spannagle, M. 2000. A method for estimating the relative likelihood of failure of embankment dams by internal erosion and piping, Canadian Geotechnical Journal 37(5): 1025-1061. http://dx.doi.org/10.1139/t00-029

Green, S. D. 2001. Towards an integration script for risk and value management, International Project Management Journal 7(1): 52-58.

Harr, M. E. 1987. Reliability based design in civil engineering. USA: McGraw-Hill Inc. 291 p.

Hartford, D. N. D.; Baecher, G. B. 2005. Risk and uncertainty in dam safety. CEA Technologies Dam Safety Interest Group, Thomas Telford Publishing. 391 p.

Kim, S.-G. 2010. Risk performance indexes and measurement system for mega construction projects, Journal of Civil Engineering and Management 16(4): 586-594. http://dx.doi.org/10.3846/jcem.2010.65

Kirk, D. Q. 1995. The integration of value management and risk management, in Proc. of the SAVE Conference, $62-72$.

Kwok, E. C. S.; Anderson, P. M.; Ng, S. H. S. 2010. Value engineering for railway construction projects: cost driver analysis, in Proceedings of the Institution of Mechanical Engineers, Part F: Journal of Rail and Rapid Transit 224(F1), 45-52. http://dx.doi.org/10.1243/09544097JRRT291

Lacasse, S.; Nadim, F.; Hoeg, K.; Gregersen, O. 2004. Risk assessment in geotechnical engineering: the importance of engineering judgment, in Proc. of Advances in Geotechnical Engineering: The Skempton Conference, 29-31 March, 2004, London, UK, 856-867.

Lee, M. J.; Lim, J. K.; Hunter, G. 2010. Performance-based value engineering application to public highway construction, KSCE Journal of Civil Engineering 14(3): 261-271. http://dx.doi.org/10.1007/s12205-010-0261-y

Leung, M.-Y.; Ng, S. T.; Cheung, S.-O. 2002. Improving satisfaction through conflict stimulation and resolution in value management in construction projects, 
Journal of Management in Engineering ASCE 18(2): $68-75$. http://dx.doi.org/10.1061/(ASCE)0742-597X(2002)18:2(68)

Manik, A.; Gopalakrishnan, K.; Singh, A.; Yan, S. 2008. Neural networks surrogate models for simulation payment risk in pavement construction, Journal of Civil Engineering and Management 14(4): 235-240.

Phoon, K. K. 2004. Towards reliability-based design for geotechnical engineering, in Special Lecture for Korean Geotechnical Society, 9 July, 2004, Seol. 23 p.

PRC Engineering. 1987. Tongue river dam risk assessment. Report to the State of Montana Department of Natural Resources and Conservation, USA.

Rajabalinejad, M. 2009. Reliability methods for finite element models. PhD thesis. Delft University of Technology, Delft, The Netherlands. 120 p.

Salmon, G. M.; Hartford, D. N. D. 1995. Risk analysis for dam safety, International Journal of Rock Mechanics and Mining Sciences and Geomechanics Abstracts 32(6): 284A.

http://dx.doi.org/10.1016/0148-9062(95)99263-W
Sellmeijer, J. B.; Koenders, M. A. 1991. A mathematical model for piping, Applied Mathematical Modeling 15(11-12): 646-651. http://dx.doi.org/10.1016/S0307-904X(09)81011-1

Stewart, R. A. 2000. Dam risk management, in Proc. of the International Conference on Geotechnical \& Geological Engineering (GeoEng 2000), 19-24 November, 2000, Melbourne, Australia, 19-24.

Thompson, M. 2004. Value solutions - a path to sustain infrastructure incorporating risk into value engineering. Canadian Society of Value Analysis, Toronto, Canada. Presentation. 17 p.

Vick, S. G.; Bromwell, L. G. 1989. Risk analysis for dam design in Karst, Journal of Geotechnical Engineering ASCE 115(6): 819-835. http://dx.doi.org/10.1061/(ASCE)0733-9410(1989)115:6(819)

Zavadskas, E. K.; Turskis, Z.; Tamošaitiene, J. 2010. Risk assessment of construction projects, Journal of Civil Engineering and Management 16(1): 33-46. http://dx.doi.org/10.3846/jcem.2010.03

Mohsen ROHANINEJAD. Master graduate in Civil Engineering from Iran University of Science and Technology. His publications have been presented at the 2nd International Conference on Value Engineering and Value Management, Beijing, China and 7th European Conference on Numerical Methods in Geotechnical Engineering, Trondheim, Norway. His research interests include reliability analysis, risk analysis and management, decisionmaking models, and infrastructure management.

Morteza BAGHERPOUR. Dr, Assistant Professor of Industrial Engineering at Iran University of Science and Technology. His publications have appeared in referred journals such as Expert Systems with Applications, International Journal of Production Research, International Journal of Advanced Manufacturing Technology, IMECHE: Part B: Journal of Engineering Manufacture, International Journal of Computational Intelligent Systems. He is also a member of the advisory board at the international journal of information technology project management. His primary research interests include project management systems, production management, and multi-disciplinary studies. 